\title{
As criptomoedas e os novos desafios ao sistema monetário:
} uma abordagem pós-keynesiana *

\author{
Olívia Bullio Mattos * \\ Saulo Abouchedid ${ }^{* * *}$ \\ Laís Araújo e Silva ${ }^{* * * *}$
}

\section{Resumo}

Em 2008, Satoshi Nakamoto, pseudônimo de uma pessoa desconhecida, lançou o "Bitcoin", uma criptomoeda descentralizada, com o objetivo de contornar qualquer banco ou governo e retornar a um sistema monetário mais "austero" e controlado. Após o advento do Bitcoin, várias outras criptomoedas foram criadas, suscitando um debate sobre a capacidade desses instrumentos substituírem o que atualmente usamos como "moeda". Após 10 anos de sua criação, fica claro que o Bitcoin não atingiu o seu principal objetivo, mas levantou discussões importantes no âmbito das Autoridades Monetárias. Assim sendo, esse trabalho tem dois grandes objetivos. O primeiro é mostrar que, sob uma perspectiva teórica pós-keynesiana, o Bitcoin não fará frente às moedas fiduciárias, pois está muito mais próximo de ser um ativo especulativo altamente volátil do que uma moeda capaz de assumir as funções primordiais em uma economia capitalista. O segundo objetivo é apontar os desdobramentos dessa discussão no âmbito das Autoridades Monetárias, com destaque para as propostas das criptomoedas estatais.

Palavras-chave: Moeda, Bancos Centrais, Criptomoedas, Economia monetária.

\section{Abstract \\ Cryptocurrencies and the new challenges faced by the monetary system: a post-Keynesian perspective}

In 2008, Satoshi Nakamoto, the pseudonym of an unknown person, launched 'Bitcoin', a decentralized cryptocurrency, aiming at circumventing banks or governments and returning to a more 'austere' and quantitycontrolled monetary system. After Bitcoin, several other cryptocurrencies were created, and a debate on whether these instruments could ever replace what we currently use as 'money' surfaced. Ten years since its creation, it is clear that Bitcoin did not reach its main goal but raised important discussions within the framework of Monetary Authorities. Therefore, this work has two main objectives. The first is to show that, from a post-Keynesian theoretical perspective, Bitcoin cannot stand up to fiduciary currencies because it is much closer to being a highly volatile speculative asset than a currency capable of assuming the prime functions in a capitalist economy. The second objective is to point out the consequences of this discussion within the framework of the monetary authorities, with emphasis on the proposals of central bank cryptocurrencies.

Keywords: Currency, Central Banks, Cryptocurrencies, Monetary economics. JEL E40, O33, E42, E58.

\footnotetext{
${ }^{*}$ Artigo recebido em 20 de julho de 2019 e aprovado em 21 de janeiro de 2020

${ }^{* *}$ Professora Assistente do Departamento de Economia, História e Ciência Política, St. Francis College, Nova York, EUA. E-mail: obulliomattos@ sfc.edu. ORCID: https://orcid.org/0000-0001-8797-071X.

${ }^{* * *}$ Professor das Faculdades de Campinas (Facamp), Campinas, SP, Brasil. E-mail: saulo.ab7@gmail.com. ORCID: https://orcid.org/0000-0002-5914-4311.

${ }^{* * * *}$ Mestranda em Teoria Econômica pelo Instituto de Economia da Universidade Estadual de Campinas (IE. Unicamp), Campinas, SP, Brasil. E-mail: laisaraujoesilva@gmail.com. ORCID: https://orcid.org/0000-0001-5049-9514.
} 


\section{Introdução}

Em 2008, Satoshi Nakamoto, pseudônimo de uma pessoa desconhecida, lançou o "Bitcoin", uma criptomoeda descentralizada, com o objetivo de retirar o controle da moeda estatal e privada das mãos dos bancos e Bancos Centrais e retornar a um sistema monetário mais "austero" e controlado. A criação do Bitcoin sintetiza as reivindicações de grupos anarquistas nos anos 1980 e 1990, que viam na criptografia um instrumento poderoso contra a regulação e supervisão governamental. O Bitcoin - assim como as demais criptomoedas que surgiram desde então - é transacionado num sistema de pagamentos descentralizado (DLT) e sem a presença de intermediários financeiros (peer-to-peer), conhecida como blockchain. A validação de cada transação é garantida não por uma instituição específica, mas por qualquer computador conectado à rede de Bitcoin.

A evolução do Bitcoin entre 2008 e 2018, no entanto, problematiza o objetivo inicial de seus criadores e desenvolvedores. Apesar do aumento da aceitação e do volume de transações denominadas nessa criptomoeda, as valorizações abruptas e intensas e as grandes variações diárias na cotação em relação ao dólar sugerem um comportamento semelhante ao de um ativo utilizado, principalmente, para fins especulativos. Na sua concepção original, o Bitcoin conseguiria fazer frente à moeda emitida pelos Estados, servindo como unidade de conta, meio de troca e reserva de valor. No entanto, uma análise mais cuidadosa das características de instrumentos monetários em uma economia capitalista contemporânea sugere que dificilmente a moeda estatal será substituída por criptomoedas como o Bitcoin, embora haja um potencial significativo para o uso dessas tecnologias em um sistema de pagamento coordenado pelos Bancos Centrais.

Assim sendo, este artigo pretende fazer essa argumentação com quatro seções. $\mathrm{Na}$ primeira, é feita uma discussão de o que é moeda e o que são instrumentos financeiros/ de dívida a partir de uma análise pós-keynesiana. Na segunda seção, discute-se a centralidade dos bancos e especialmente dos Bancos Centrais no sistema de pagamentos modernos, a fim de garantir a estabilidade financeira e evitar crises sistêmicas. Na terceira seção, apresenta-se o surgimento das criptomoedas e do Bitcoin, do seu funcionamento e de sua evolução. Nesta seção, também são discutidas as formas como os Bancos Centrais estão pretendendo adotar essas novas tecnologias em suas operações. Na quarta e última seção, os comentários finais são dedicados à discussão teórica de se as criptomoedas podem tornar-se efetivamente moeda no sistema contemporâneo, e às contradições verificadas das criptomoedas em relação aos seus ideais originais. Por fim, nessa seção são feitas considerações sobre possíveis desdobramentos do potencial disruptivo das criptomoedas e dos novos sistemas de pagamentos DLT para os Bancos Centrais.

\section{A hierarquia da moeda}

A questão "o que é moeda" intriga os estudiosos em Economia há séculos. Foi (e continua sendo) em muitos dos debates o principal ponto de divergência entre escolas de 
pensamento econômico. A forma como determinada escola enxerga o que é moeda e o seu papel em uma economia capitalista molda o seu entendimento sobre o próprio funcionamento do sistema, sobre o comportamento e objetivo de agentes econômicos, e sobre a forma de gestão da política econômica por parte do Estado (e, no fundo, qual o verdadeiro papel estatal).

No Treatise on Money (Volume I - Pure Theory of Money) escrito em 1930, J. M. Keynes destaca que a primeira função exercida pela moeda é a de ser unidade de conta, ou seja, aquilo no qual preços e dívidas são expressos. Essa função emerge da necessidade de "medir" contratos em um mesmo padrão monetário e é a mais abstrata e conceitual das funções da moeda. As outras funções, a de ser meio de pagamento ${ }^{1}$ (o que Keynes chama de money itself ou money proper, que é a "coisa" usada para liquidação de contratos, é a representação concreta da moeda, o "papel dinheiro") e a de ser reserva de poder de compra no tempo, são derivadas da primeira. O Estado tem o poder de determinar "what thing corresponds to the name, and to vary its declaration from time to time - when, that is to say, it claims the right to re-edit the dictionary" (Keynes, 1971, p. 4). Assim, a moeda é, primeiramente, uma "criatura do Estado"2.

O centro de uma economia monetária da produção analisada por Keynes é o sistema de crédito-débito que baliza as relações sociais e econômicas de um sistema capitalista. Quando moeda é criada, ela é, ao mesmo tempo, ativo para quem carrega e passivo para quem emite. Moeda é crédito e dívida, duas representações da mesma obrigação legal, e 'nasce' quando credor e devedor entram em uma promessa formal (contrato) de pagamento no futuro (Bell, 2001).

Mesmo que o processo de criação de dívida pela concessão de crédito seja uma simples operação contábil, o que permite que qualquer agente o faça, a criação de moeda se dá pela aceitação desse registro contábil por outros como instrumento de pagamento. Como colocado por Bell (2001, p. 151): “[...] an offer to go into debt (to add a liability to a balance sheet) does not materialize into money until another party agrees to hold that liability (to add it to the asset side of its balance sheet)." Ainda, a simples aceitação dessa representação de dívida por outro agente não garante que o instrumento circule como moeda, o que necessita de uma aceitação generalizada. Em um sistema monetário, duas instituições são capazes de criar estes instrumentos: o Banco Central e os bancos comerciais. O primeiro cria papel-moeda usado pelo público não-bancário e reservas bancárias, utilizadas pelos bancos no sistema de pagamentos. Os segundos criam depósitos à vista, um passivo para os bancos gerado quando estes decidem adquirir um ativo, como empréstimos.

(1) Chick (2010, p. 194), mencionando Shackle, coloca que há uma diferença entre a função de meio de troca e de meio de pagamento. O pagamento é aquilo que é considerado como final, quando nenhum "contato adicional entre as partes é requerido ou esperado". Ou seja, o contrato foi finalizado, a dívida foi paga, e isso se dá naquilo que é considerado moeda. Para a troca, podem ser aceitos outros ativos, como por exemplo um crédito, que adia o pagamento em si, mas não o finaliza.

(2) Wray (1998) apresenta uma abordagem cartalista da moeda, também colocada por Keynes (1971). A moeda é criatura do Estado porque ele obriga o pagamento de tributos com a moeda que ele mesmo emite. Como todos os agentes "devem" ao Estado, a moeda emitida é aceita sem contestação. 
A criação de moeda bancária é endógena, isto é, o banco é capaz de acompanhar a demanda por empréstimos, desde que essa operação seja atraente, sem que possua nenhum recurso prévio, como reservas ou depósitos. Como a moeda bancária criada é considerada meio de pagamento, assim como a moeda emitida pelo Estado, esse sistema necessita de uma instituição hierárquica capaz de garantir a paridade entre moeda bancária e moeda estatal (ou seja, que a troca entre um e outro não se dê a preços de "mercado", mas sim em "um para um", ao "par"). Essa instituição é o Banco Central, que através da política monetária e na sua atuação como emprestador de última instância, cria liquidez e garante que a paridade não seja colocada em risco e a confiança no sistema financeiro como um todo não seja abalada. A moeda bancária é, para Keynes (1971), um reconhecimento de dívida privada que é transformada em money proper através do poder do Estado de declarar que ela é capaz de liquidar outras dívidas e garantir esse papel.

A moeda é pensada por Keynes como a representação da riqueza abstrata, e nesse sentido, em uma economia sujeita à incerteza, pode ser demandada por ela mesma e retida como um ativo, subtraindo a demanda por outros ativos, inclusive aqueles reprodutíveis, geradores de emprego e renda. A moeda é, na realidade, um ativo único pela sua flexibilidade e segurança, uma vez que não precisa ser convertida em nada mais, ela já é a própria riqueza. E pode cumprir este papel por ter elasticidade de produção zero (sua oferta não cresce facilmente quando há aumento da demanda, o ajuste se dá pela taxa de juros monetária) e elasticidade de substituição zero (não há outro ativo capaz de satisfazer a demanda por moeda). Apesar de não render juros, a posse de moeda acalma as inquietações dos agentes frente a um futuro incerto.

Assim, na concepção Keynesiana de uma economia monetária da produção, a moeda circula na esfera industrial, na qual "preserva-se o espaço da moeda como meio de troca, girando produtos e serviços” (Carvalho, 1992, p. 169), mas também na esfera financeira ${ }^{3}$, onde a moeda é retida de acordo com as expectativas dos agentes em relação à taxa de juros ${ }^{4}$, que são incertas e podem ser revertidas rapidamente. Nesta esfera, a moeda é realmente reserva de valor, o ativo com atributo de liquidez máxima e faz parte do estoque de riqueza. Se há expectativa de variação da taxa monetária de juros no futuro, os agentes podem optar por reter

(3) As esferas industrial e financeira são colocadas por Keynes no Treatise on Money. Na Teoria Geral, essas esferas tornam-se os "motivos para demandar moeda". Na esfera industrial, encontra-se o motivo transação: a demanda por moeda que depende diretamente da renda para realização de transações correntes, hoje ou no futuro. Na esfera financeira, estão os motivos precaução, no qual a moeda é retida para algum evento inesperado e está relacionado com a função da moeda como um portoseguro; e o motivo especulação, no qual a retenção de moeda se dá para ganhos especulativos no mercado de títulos. Aqui, os agentes podem demandar títulos se esperam que seu preço suba no futuro e a taxa de juros caia (Keynes chamou estes agentes de altistas ou touros) ou demandar moeda, caso esperem que o preço dos títulos caiará e sua taxa subirá (baixistas ou ursos). A política monetária age neste último motivo, pois o $\mathrm{BC}$ tem a capacidade de alterar a quantidade de moeda e influenciar as expectativas dos agentes quanto à taxa de juros. A taxa de juros é, assim, um fenômeno monetário e é determinada pela preferência dos agentes em como manterão suas reservas monetárias (moeda ou títulos) e pela oferta de moeda do BC. É importante destacar que Keynes está se referindo à taxa de juros de longo prazo.

(4) Importante colocar que essa taxa de juros é aquela de longo prazo, que influencia as decisões de investimento. 
moeda ou títulos com fins especulativos ${ }^{5}$, influenciando o nível da taxa de juros hoje. Em uma economia monetária da produção, a velocidade de circulação da moeda é instável e os agentes deparam-se continuamente com a decisão de como alocar seu estoque de riqueza. Se há preferência pela liquidez, a retenção de moeda na esfera financeira afeta o preço dos demais ativos, tendo consequências sobre a esfera real.

Wray e Papadimitriou (2010) colocam que a moeda é um "IOU" - I Owe You -, um reconhecimento de dívida. A moeda estatal hoje, moeda fiduciária, é uma dívida do $\mathrm{BC}$, e não há nenhuma conversibilidade prometida em outro ativo. Esta, juntamente com outros instrumentos financeiros emitidos, que são dívidas privadas, formam uma hierarquia (Figura $1)^{6}$, que não é estática. O IOU emitido pelo Estado sempre está no topo, pois é considerado o meio de pagamento último e mais líquido, e os que estão abaixo dele são ordenados conforme sua conversibilidade na moeda estatal. Os diversos ativos financeiros emitidos se diferenciam, assim, pelo seu grau de liquidez - a possibilidade de conversão à moeda estatal rapidamente e sem perda de valor - o que, por sua vez, não é uma característica fixa do ativo, mas sim "depende da organização das finanças e do regime monetário que determinam conjuntamente as condições nas quais esse ativo pode ser transformado na liquidez última" (Aglietta, 2004, p. 78). Assim, a liquidez de um ativo é determinada, no fundo, pela sua capacidade de ser transacionado em mercados. A condução e organização do sistema bancário e o acesso, em última instância, ao BC, pressupõe a conversibilidade e manutenção da paridade da moeda bancária (o "par") com a moeda estatal e da sua aceitação generalizada como moeda.

No entanto, a moeda bancária é hierarquicamente inferior (por isso a linha "pontilhada" da figura) pela possibilidade de haver corridas bancárias (ainda que essa possibilidade seja menor nos sistema financeiros contemporâneos que contam com seguros de depósitos), quando os agentes "correm" para a liquidez da moeda estatal e pela própria organização dos sistemas de pagamentos modernos, onde o pagamento final de transações com moeda bancária é realizado pela compensação com reservas bancárias (portanto, com moeda estatal). Abaixo na hierarquia estão as quase-moedas e outros ativos financeiros emitidos por agentes privados e que podem ser considerados mais ou menos líquidos, a depender da sua qualidade e facilidade de conversão. Há uma hierarquia também dentro desse estrato, de acordo com a liquidez das diversas quase-moedas. Importante ressaltar que estes instrumentos financeiros são emitidos por algum agente com pelo menos uma de duas promessas no futuro, segundo Tymoigne (2013): de conversão em alguma outra coisa, como moeda estatal; ou de que serão aceitos de volta pelo emissor. Ativos reais ou commodities, como ouro, por exemplo, não são instrumentos financeiros pois não contêm nenhuma promessa. Já as moedas em ouro podem ser consideradas instrumentos financeiros pois prometem a quantidade de ouro "embutida"

(5) De acordo com Kaldor (1939 apud Aglietta, 2004, p. 44), especulação é "a compra (ou venda) de mercadorias tendo em vista uma revenda (ou recompra) em data posterior, onde o móbil de tal ação é a antecipação de uma mudança dos preços em vigor, e não uma vantagem resultante de seu uso, ou uma transformação ou transferência de um mercado para o outro."

(6) Elaboração própria com base nas aulas do Professor Perry Mehrling, da Universidade de Columbia, disponíveis no site Coursera (Economics of Money \& Banking, Part I, 2013). 
nelas. Ainda, todo ativo financeiro é ativo para quem carrega e passivo para quem emite, inclusive a moeda estatal: "Currency is their liability because they (at least) promise to take their currency from bearers in payments at any time; issuers owe that to the bearers" (Tymoigne, 2013, s.p.).

Carvalho (1992) corretamente coloca que a liquidez de ativos privados é maior quanto mais organizados forem os mercados para sua comercialização ${ }^{7}$ e pela existência de um market $^{2}$ maker, que é aquele agente que impede flutuações de preços e coloca-se como comprador e/ou vendedor dos ativos. O conceito de liquidez também tem a ver com o tempo, isto é, de como é montado o cronograma de recebimentos e pagamentos. Mesmo que um ativo seja considerado de "boa qualidade" hoje, o seu emissor pode incorrer em problemas de liquidez caso seu balanço seja muito descasado no tempo, levando a default no ativo "bom". Mehrling (2000) coloca que, por este motivo, não há possibilidade de haver um sistema monetário totalmente privado, uma vez que o BC é a única instituição que nunca incorre em problema de liquidez.

Figura 1

A hierarquia de instrumentos financeiros

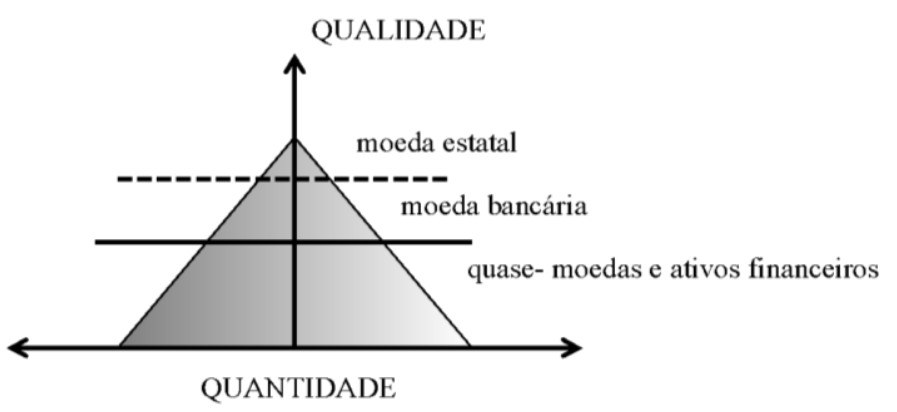

Fonte: Elaboração própria.

Segundo Guttmann (2003), a moeda tem uma "natureza dual": é um bem público, cujas funções devem ser preservadas, mas também é criada privadamente com objetivos de lucro. Belluzzo e Almeida (2002, p. 28) e Belluzzo (2012), na mesma linha, colocam que as funções da moeda dependem do seu funcionamento como "fundamento das relações entre produtores independentes" e, ao mesmo tempo, como o único critério de quantificação do enriquecimento privado. Estes dois lados da moeda podem ser conflituosos, já que a busca incessante pelo enriquecimento individual pode levar à ruptura do caráter público. O Banco Central tem, assim, o papel de administrar a "norma" monetária, conduzindo os dois lados da moeda de forma equilibrada e organizando os espaços nos quais os agentes buscam o enriquecimento, a fim de garantir a soberania da moeda estatal: "O Banco Central assume a função de coordenador das

(7) Segundo Aglietta (2004), os mercados são mais líquidos quanto maiores as suas: i) amplitude - deve haver um grande volume de títulos e de agentes com objetivos diversificados; ii) profundidade - preços devem variar pouco com a operação marginal dos agentes e iii) resiliência - que tem a ver com a velocidade com que o preço se ajusta quando o mercado é atingido por um choque exógeno. A existência de câmaras de compensação garante que os mercados serão mais líquidos. 
expectativas privadas que governam as decisões sobre a posse da riqueza" (Belluzzo, 2012, p. 115). Esse é o papel da autoridade monetária em todos os momentos, seja em períodos "normais", seja em uma crise. Quando um banco fornece um empréstimo, ele cria um depósito à vista na conta corrente do tomador, que será então usado por este como meio de pagamento. A validação dessa moeda se dá pela intermediação do $\mathrm{BC}$ nas operações dos bancos com moeda estatal na forma de reservas bancárias, usadas para as compensações. O BC deve, ao mesmo tempo, garantir a validade da moeda bancária e tentar controlar a sua criação, preservando a sua qualidade e não deixando o lado público da moeda ser comprometido pela sua criação privada.

Ainda que a concepção de moeda apresentada aqui seja a da prioridade à sua função de unidade de conta e das relações crédito-débito, o mito de que a moeda surgiu para facilitar trocas, que ocorreriam "naturalmente" em sociedades com indivíduos propensos à troca pacífica, ainda domina o pensamento econômico. As criptomoedas, em especial o Bitcoin, que serão discutidas nas sessões posteriores, têm por detrás essa visão, já que seus criadores acreditam que elas poderiam substituir a moeda criada pelo Estado, ou mesmo a criada pelos bancos, nas suas funções básicas.

\section{Bancos e sistemas de pagamentos}

Conforme colocado, as Autoridades Monetárias têm poder de criar dois "tipos" de moeda: notas e moedas metálicas que estão disponíveis para todos os agentes econômicos, e moeda eletrônica em forma de saldos em contas de reserva e compensação disponíveis aos bancos no Banco Central.

Quando o público realiza pagamentos utilizando instrumentos bancários, surge a necessidade de os bancos transferirem recursos entre si, realizando a compensação do pagamento. Essa transferência, eletrônica, pode ser feita de duas formas: através de contas correntes em outros bancos (chamadas de contas "nostro" ou "vostro"), ou através das contas de compensação no Banco Central, utilizando reservas bancárias, a maneira mais comum.

A liquidação de pagamentos nas contas no BC pode ter, por sua vez, dois formatos. Em um sistema de compensação pelo valor líquido (LDL), há a transferência de fundos pela posição líquida de cada participante. A necessidade de reservas é reduzida, mas o risco de crédito é maior pela defasagem de tempo. No segundo formato, um sistema de compensação pelo valor bruto em tempo real (LBTR), as bases de transferência de recursos são contínuas e instantâneas, em tempo real. A liquidação das obrigações é feita uma a uma, em tempo real. Os riscos são menores, mas há necessidade de maior nível de reservas bancárias. Em ambos os formatos, o BC funciona como uma clearing, pois nenhuma outra ação é necessária após os fundos de reservas bancárias serem transferidos pelo $\mathrm{BC}$.

O bom funcionamento do sistema de pagamentos é de interesse público, já que uma crise na liquidação pode rapidamente tornar-se sistêmica. Assim, na maioria dos países, o papel de manter saudável o sistema de pagamentos cabe ao Banco Central (BIS, 2003), centralizando 
a liquidação e exigindo que a mesma seja feita com moeda (dívida) emitida por ele próprio. Essa é uma propriedade hierárquica fundamental de sistemas monetários contemporâneos: os pagamentos entre agentes econômicos não-bancários são realizados, em sua maioria, utilizando moeda (dívida) bancária, com transferência de recursos em forma de depósitos (também podem ser realizados diretamente com moeda física emitida pelo BC). Estes mesmos pagamentos serão compensados pelos bancos, mas a transferência de recursos entre eles e a liquidação dos pagamentos não é feita com moeda emitida pelos bancos, mas pelo $\mathrm{BC}$ (reservas bancárias). Isso garante que o $\mathrm{BC}$ tenha controle sobre o sistema de pagamentos, mantenha a estabilidade financeira e evite crises de desconfiança no sistema bancário. A emissão de moeda pelos bancos é, assim, garantida pela atuação do BC no sistema de pagamentos, para que não haja desvalorização do "par" de uma ou outra instituição bancária.

\section{As criptomoedas privadas e estatais}

Conforme colocado por He (2018), a crise financeira de 2008 e a desconfiança tanto nos bancos, com operações fraudulentas e arriscadas que levaram ao colapso, quanto nos Bancos Centrais, que socorreram estes mesmos bancos com maciças injeções de liquidez nos sistemas financeiros, fez surgir movimentos de contestação ao sistema monetário tradicional com criação de novas criptomoedas, emitidas e utilizadas de forma descentralizada:

The loss of trust in the fiat currency system, caused mainly by quantitative easing and huge government debts, has brought attention to cryptocurrency for those who wanted to hedge their positions with a currency that has a finite supply (Chuen, 2015, p. 10).

Embora seja um fenômeno recente, as raízes das criptomoedas (e das moedas digitais) remontam aos anos 1980, quando David Chaum, por meio da empresa Digicash, desenvolveu o conceito de moeda digital, que, dentre outras características, envolvia a privacidade e o anonimato por meio da criptografia. Seguindo as mesmas características da Digicash, surgiram outras moedas digitais, dentre elas a Hashcash (Back, 1997) e o b-money (Dai, 1998), e também inovações importantes, como a tecnologia proof of work $^{8}$ (posteriormente conhecida como mineração), que conferiu segurança às operações com moedas digitais. Grande parte das moedas digitais e inovações supracitadas eram produtos do movimento Cypherpunk e/ou Crypto Anarchist, grupos ativistas que consideravam a criptografia um instrumento revolucionário e fundamental para mudanças políticas e sociais:

Just as the technology of printing altered and reduced the power of medieval guilds and the social power structure, so too will cryptologic methods fundamentally alter the nature of corporations and of government interference in economic transactions (May, 1992, p. 1).

No entanto, apesar de possuírem um caráter inovador, as moedas digitais citadas se tornaram somente uma forma da moeda fiduciária, isto é, ainda estavam sujeitas à regulação e

(8) Proof of work refere-se ao processo (de cálculo) requerido ao servidor para que uma transação seja validada. Esse mecanismo protege o sistema de ataques ou abusos como spam (Lee; Chuen, 2017). 
supervisão das autoridades monetárias dos países em questão (Peters et al., 2015; Huberman et al., 2017). Assim, ainda que haja semelhanças entre moedas digitais e criptomoedas, apenas essa última possui o caráter disruptivo tão aclamado pelos grupos Cypherpunks e Crypto Anarchists: são moedas digitais utilizadas em um sistema de pagamentos descentralizado e peer-to-peer ${ }^{9}$, sem sujeição, portanto, a um órgão regulador ou supervisor centralizado (Huberman et al., 2017). Dessa forma, as criptomoedas nascem com o ambicioso objetivo de se desvencilhar da moeda fiduciária, se tornando uma moeda "debt-free" - isto é, não são passivos de nenhum outro agente -, com oferta limitada (Chuen, 2015).

Dentre as diversas criptomoedas, como Ethereum, XRP, Cardano, Stellar, etc., o Bitcoin, desenvolvido por Nakamoto (2008), se destacou ao se propagar rapidamente não apenas entre membros e simpatizantes dos movimentos pró-criptografia, mas também entre os agentes dos mercados financeiros e famílias. O Bitcoin, assim como as demais criptomoedas, opera num sistema de pagamentos global, descentralizado, sem a presença de intermediários financeiros (peer-to-peer) e distribuído - ou seja, todos os computadores que possuem acesso ao sistema são capazes de minerar Bitcoins e outras criptomoedas (Chuen, 2015). Ademais, a oferta é limitada em 21 milhões de Bitcoins, a fim de evitar movimentos expansionistas descontrolados.

De modo geral, esse sistema de pagamentos se baseia numa tecnologia conhecida como Distributed Ledged Technology (DLT), que se refere aos "protocols and supporting infrastructure that allow computers in different locations to propose and validate transactions and update records in a synchronised way across a network" (BIS, 2017, p. 58). O DLT mais comum é aquele cujas transações são transmitidas para todos os conjuntos de participantes que trabalham para validá-las em lotes conhecidos como blocos (ou blocks). Embora esses blocos sejam separados, eles são conectados pelos protocolos e infraestrutura em comum, necessários para minerar as criptomoedas. Dessa forma, este tipo de DLT, no qual se baseia o Bitcoin, também é conhecido como blockchain (Bech; Garratt, 2017, p. 58).

O funcionamento do Blockchain pode ser verificado na Figura 2 que representa a transferência de Bitcoins (ou BTC) do agente A para o agente B. Num primeiro momento, os Bitcoins saem da e-wallet (conta na rede blockchain) do agente A e entram na e-wallet do agente $\mathrm{B}$ em poucos segundos, porém pendente de validação. Essa validação ocorrerá no sistema DLT, no qual diversos computadores participantes concorrerão para validar a transação por meio da finalização do proof-of-work (mineração) necessário para criar um novo bloco, que satisfaz todos os protocolos requeridos pelo sistema DLT. O primeiro computador a criar o bloco ganha como recompensa alguns Bitcoins; o novo bloco, por sua vez, é propagado pela rede e outros computadores irão checar se o bloco é válido - já que o sistema é descentralizado, ou seja, não há um órgão central que faz essa validação - antes de incluí-lo no sistema

(9) Conforme Peters et al. (2015), num ambiente peer-to-peer, a validação das transações deve ser aprovada por mais de $50 \%$ dos computadores conectados ao sistema. 
blockchain. Após esse processo, o agente B receberá a confirmação da transação dos Bitcoins enviados pelo agente A.

Figura 2

Funcionamento básico do Blockchain

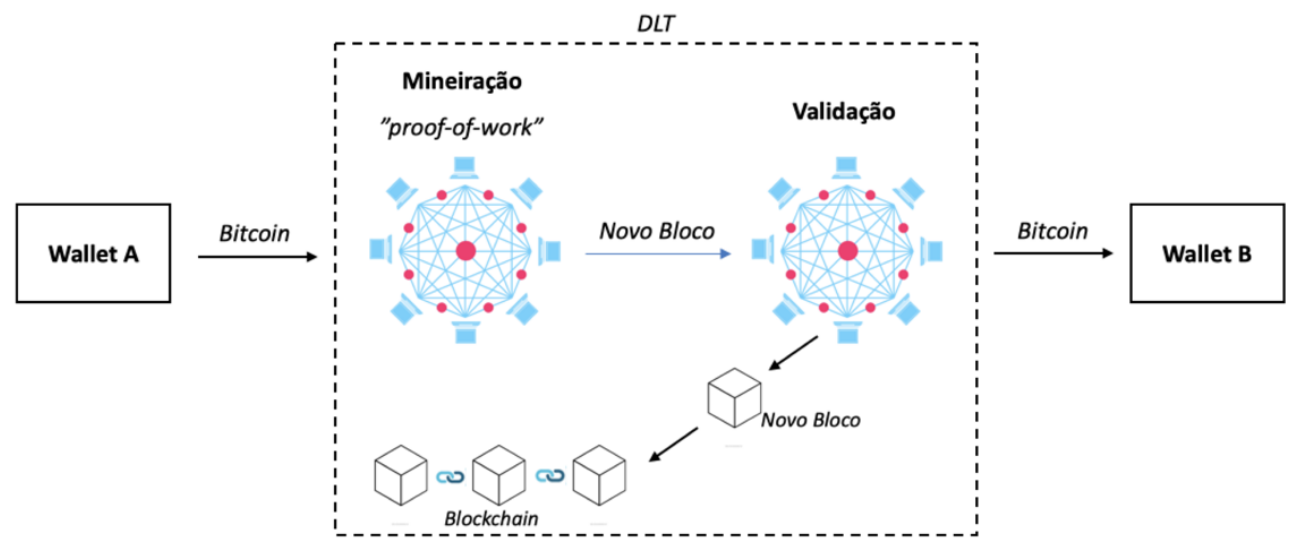

Fonte: Elaboração própria.

Conforme mencionado, o Bitcoin foi a primeira criptomoeda a se destacar, ao transpor as fronteiras da deep web - ambiente anárquico, sem a presença governamental - e do submundo do crime ${ }^{10}$ em direção aos mercados financeiros, com cotações em dólares e outras moedas nacionais. Além disso, a Bolsa de Mercadorias de Chicago (CME Group) lançou em 2017 contratos futuros de Bitcoin, e anunciou que contratos de opção passarão a ser negociados em janeiro de 2020. Embora o volume de transações em Bitcoins tenha se mantido estável entre 2010 e 2018, tanto a valorização dessa criptomoeda em relação ao dólar quanto a variação semanal da taxa BTC/US \$ alcançaram valores expressivos no mesmo período (ver Gráficos 1 e 2 respectivamente ${ }^{11}$ ). Conforme o Gráfico 2, após uma rápida valorização entre 2012 e 2013 - que foi revertida com a quebra de casas de câmbio de Bitcoins na China e no Japão - a taxa BTC/US\$ volta a ganhar relevância em 2016 e se valoriza expressivamente em 2017.

Portanto, ainda que a aceitação do Bitcoin (e de outras criptomoedas) tenha aumentado no período analisado ${ }^{12}$, seu comportamento se assemelha ao de um ativo (conforme explicado na próxima seção), negociado por meio de casas de câmbio especializadas - uma espécie de intermediário financeiro que se multiplicou nos últimos anos - e sujeito a variações diárias, fatores que fomentam movimentos especulativos (Chuen, 2015). Esse comportamento levou à

(10) Conforme Forbes (2017), o Bitcoin ganhou alguma liquidez (e atenção) “após a página Silkroad, na deep weeb, vender mercadorias ilícitas e somente aceitar Bitcoins nas transações".

(11) O Gráfico 1, sobre o volume de transações, considera somente a fase recente de valorização do Bitcoin e das demais criptomoedas, entre 2015 e 2018.

(12) Vale ressaltar o uso do Bitcoin e outras criptomoedas em situações de crises financeiras extremas. Por exemplo, a iminência de uma corrida bancária no Chipre em 2011 - gerada pelo agravamento da crise na zona do euro - levou muitos depositários a converter seu dinheiro em Bitcoins e outras criptomoedas (Lee; Chuen, 2015). 
formação da maior bolha especulativa da história, em 2017 e, após seu "estouro" no mesmo ano, pode levar à formação de uma espiral deflacionária, conforme a oferta de Bitcoins vai chegando ao seu limite (Bloomberg, 2018; Peters et al., 2017).

Gráfico 1

Volume de transações diárias em Bitcoins (2011-2019)

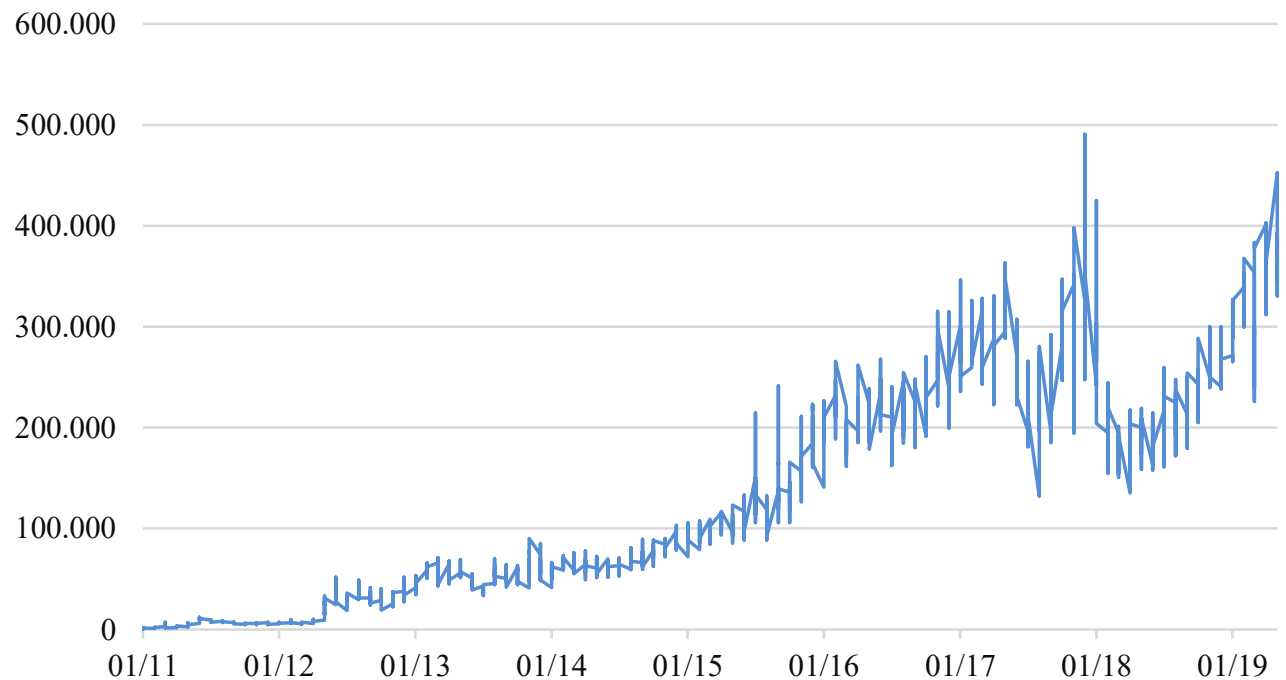

Fonte: https://www.blockchain.com/ (blockchain.com/stats)

Gráfico 2

Cotação BTC/US\$ e variação semanal (01/2011 a 01/2019)

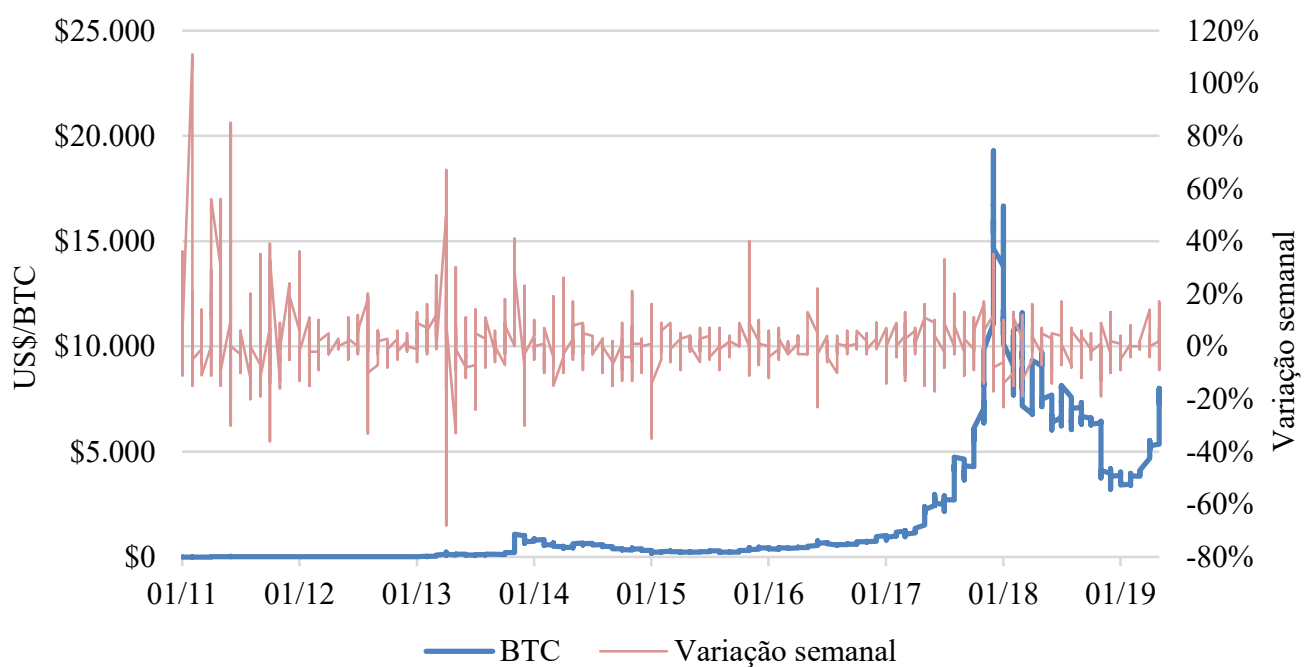

Fonte: https://www.blockchain.com/ (blockchain.com/stats) 
O comportamento do Bitcoin e das outras criptomoedas ao longo do período supracitado afetou também algumas características essenciais das próprias criptomoedas e do sistema DLT a elas vinculados. A presença das casas de câmbio especializadas, por exemplo, impacta o caráter descentralizado do blockchain, já que as operações de tais instituições estão sujeitas a algum órgão supervisor. O caráter descentralizado e distributivo do blockchain também foi desafiado pela evolução da mineração das criptomoedas. No caso do Bitcoin, a elevação do custo de mineração ${ }^{13}$ - gasto energético necessário para a validação de uma transação - restringiu a entrada de mineradores no mercado, mesmo num cenário de grande valorização dessa criptomoeda. A elevação desse custo é resultado da própria concepção do Bitcoin: para controlar a oferta no longo prazo, o processo de mineração se torna mais difícil ao longo do tempo, elevando, portanto, o gasto energético envolvido.

Dessa forma, a necessidade de grandes servidores para se lucrar com as validações nos sistemas DLT estimulou a criação de um oligopólio no setor, agora não mais controlados por grandes bancos, mas sim por empresas de tecnologia. O Gráfico 3 abaixo mostra a participação de cada minerador na capacidade total de processamento de cálculos por segundo - conhecida como taxa hash - ou, em outras palavras, na capacidade total de validação das transações em Bitcoin. A Bitmain, empresa chinesa, controla a BTC.com e a AntPool, responsáveis por 37\% dessa capacidade de validação ${ }^{14}$. Portanto, as próprias regras desenhadas pelos criadores do Bitcoin para questionar o controle do sistema de pagamentos por grandes bancos promovem, ainda que em menor escala, a centralização do sistema alternativo proposto.

Gráfico 3

Principais pools de mineração de Bitcoin (28/05/2019 a 31/05/2019)

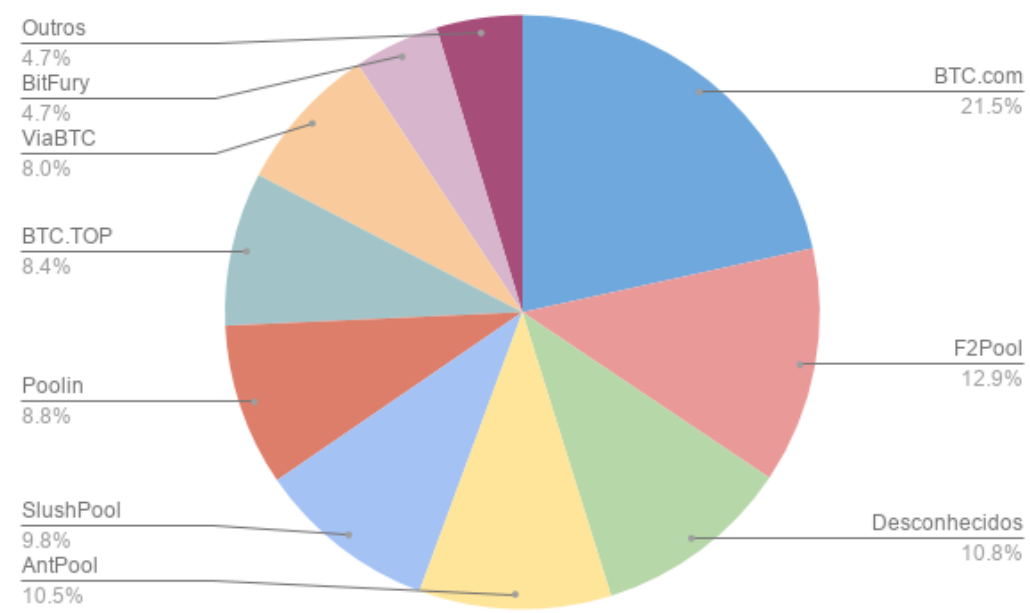

Fonte: https://www.blockchain.com/ (blockchain.com/stats).

(13) Vale ressaltar que o alto custo energético envolvido na mineração pode ser em parte compensando financeiramente pelas emissões de novas criptomoedas.

(14) Conforme o Portal do Bitcoin (2018), a Bitmain chegou a controlar 51\% do poder de processamento da rede Bitcoin. A empresa chinesa é avaliada (2018) em US\$ 8,8 bilhões e deve realizar um IPO em breve. 
Embora haja controvérsias entre o Bitcoin (e as demais criptomoedas) e as suas concepções originais, a importância dos sistemas de pagamentos DLTs para o futuro dos sistemas monetários e financeiros é um consenso entre bancos e Bancos Centrais. Em relação aos bancos, Santander, J.P. Morgan e BBVA estão desenvolvendo seus próprios sistemas de pagamentos DLT. No caso do banco espanhol, o novo sistema blockchain foi desenvolvido para transferências internacionais em moeda estrangeira (Financial Times, 2018a e 2018b). Embora seja uma opção válida para transferências internacionais, a baixa capacidade de validação de transações dos sistemas DLT em comparação aos sistemas de pagamentos domésticos tradicionais, como Visa e Mastercard, é ainda uma importante barreira de entrada no setor.

No caso dos Bancos Centrais, algumas autoridades monetárias e acadêmicos anunciaram pesquisas e experimentações com o sistema de pagamentos DLT, bem como prospectos de criptomoedas (ou moedas digitais) estatais - Canadá, África do Sul e Venezuela, por exemplo. No campo teórico, a principal dificuldade reside na definição da criptomoeda estatal e sua classificação junto aos outros tipos de moeda estatal e privada. BIS (2017) propõe uma taxonomia para as criptomoedas estatais (Central Bank Criptocurrencies). Assim como as criptomoedas privadas, tais moedas digitais operariam num sistema peer-to-peer (sem a presença de intermediários financeiros) e global (ou universalmente acessível), porém seriam emitidas exclusivamente pelo Banco Central (assim como as reservas, outro tipo de moeda eletrônica do Banco Central), se tornando um passivo da autoridade monetária. A taxonomia ainda subdivide as criptomoedas estatais em outras duas possíveis formas: uma destinada ao varejo, isto é, uma moeda digital emitida pelos Bancos Centrais diretamente para as transações de bens e serviços do público, fora, portanto, do sistema bancário; e outra destinada às transferências no mercado interbancário. Percebe-se, portanto, que o elemento disruptivo principal das criptomoedas - a ausência de um órgão supervisor centralizado - se perde na criação das criptomoedas estatais. No entanto, características importantes como a própria criptografia (e o anonimato nas transações) e o peer-to-peer garantem o status de inovação financeira para as criptomoedas estatais (Bech; Garratt, 2017).

Conforme mencionado, Canadá e África do Sul conduzem projetos pilotos para desenvolver criptomoedas estatais destinadas ao mercado interbancário. No caso canadense, há um claro comprometimento com a compreensão profunda das novas tecnologias associadas às moedas digitais. O Projeto Jasper - o experimento do Banco Central em uma tecnologia de registro decentralizada - foi uma iniciativa feita em um trabalho conjunto com o Sistema de Pagamentos Nacional Canadense, bancos privados do Canadá e a fintech R3. A organização do projeto envolveu, de acordo com Garratt (2016), três fases baseadas em uma simulação de transferência de fundos. Em linhas gerais, os bancos privados envolvidos realizaram essa transferência de fundos entre si em uma única conta atrelada ao Banco Central do Canadá utilizando o CAD-coin, a moeda criptografada estatal. O CAD-coin funcionou como um recibo de depósito, dando o direito sobre o valor em moeda convencional do Banco Central (reservas) "ao par". A validação da transação foi garantida pela atuação de diversos dispositivos da R3 
conectados à rede, e as CAD's foram mantidas nas carteiras dos bancos em um sistema de registro descentralizado (DLT) sem que houvesse ao longo dessa simulação ajustes automáticos nas contas de liquidação da Autoridade Monetária. A atualização nas contas de liquidação do Banco Central ocorreu apenas na fase de saque, no momento em que os bancos resgataram a moeda convencional (reservas) através da conversão das CAD’s.

Essa simulação - em que os bancos privados atuaram fazendo as transferências de fundos e a R3 atuou com a validação das transações - tem uma característica importante e distinta do funcionamento do Bitcoin. Apesar de ter sido feita em um sistema de pagamentos e registros descentralizado, ele ainda é um sistema privado e que necessita da autorização/permissão do Banco Central. No entanto, o grande avanço do experimento com a CAD-coin nesse sistema foi de demonstrar que a moeda estatal - sob a "forma" criptográfica - pode ser transferida em um sistema DLT e permite a liquidação em uma única grande conta. Esse fator, segundo Garratt (2016), é de extrema importância porque é a parte mais difícil de um processo financeiro, que envolve a negociação, a compensação e a liquidação. Para Wilkins (2017), Vice-Governadora Sênior do Banco do Canadá, o desafio das pesquisas e experimentações nesse tema tem como grande desafio garantir a confiança no sistema e garantir que se cumpram - dentro de um sistema de pagamento descentralizado - as três funções primordiais da moeda: unidade de conta, meio de pagamento e reserva de valor. Adicionalmente, a Vice-Governadora ainda aponta a necessidade de maiores progressos em relação aos riscos operacionais e ao acesso e requerimento de participação no sistema.

Embora não haja projetos específicos, por parte dos Bancos Centrais, relacionados às criptomoedas estatais destinadas ao varejo, Koning (2014) propôs o Fedcoin, uma criptomoeda emitida pelo Fed e destinada ao público. De acordo com o autor, esta moeda digital seria conversível ao par com o dólar e teria sua oferta controlada pelo Fed. Diferentemente das criptomoedas privadas, o Fedcoin seria apenas uma alternativa à moeda soberana, compondo a base monetária juntamente com as reservas e o papel moeda em poder do público (Bech; Garratt, 2017).

\section{Reflexões finais: as criptomoedas podem se tornar 'moeda'?}

Conforme discutido na primeira seção, instrumentos considerados como moeda têm três funções fundamentais: são unidade de conta, meio de pagamento, e reserva de valor. Neste sentido, é uma "criatura do Estado", que impõe a unidade de conta e emite moeda em forma de dívida. Estes instrumentos precisam de duas condições: ter elasticidade de produção zero (não ser emitida privadamente sem controle), e de substituição zero (a demanda por moeda não "vaza" para outros ativos). A criação de moeda em um sistema monetário contemporâneo é feita pelos Bancos Centrais, que criam moeda física e moeda eletrônica usada pelos bancos (reservas bancárias), e pelos bancos comerciais, que criam depósitos à vista de forma endógena. A moeda, por ser um instrumento financeiro está, ao mesmo tempo, tanto no ativo de quem a carrega quanto no passivo de quem a emite. É uma relação de crédito-débito e um $I O U$, um 
reconhecimento de dívida e uma promessa de conversão em outro instrumento e/ou de aceitação pelo emissor no futuro.

Para que um certo instrumento circule como moeda, é essencial que seja universalmente aceito para liquidação de pagamentos, contratos e dívidas. A moeda emitida pelos bancos tem a confiança que servirá estes propósitos e assim é plenamente aceita sem contestação e "ao par". Isso é garantido porque os bancos estão, primeiramente, inseridos em um sistema bancário. Em segundo lugar, porque o Banco Central opera o sistema de pagamentos, onde as transações são liquidadas em moeda estatal.

Outras instituições privadas também emitem instrumentos que não são transacionados como moeda. São, entretanto, instrumentos financeiros pois estão, ao mesmo tempo, no passivo do emissor e no ativo do portador e contêm uma promessa futura. Estes instrumentos, juntamente com a moeda estatal e a bancária, formam uma hierarquia de dívidas, com a moeda estatal no topo.

As dificuldades de um sistema monetário coordenado pelas criptomoedas também são apontadas por Aglietta (2018, p. 173-176), a partir da visão dualista da moeda. Conforme o autor, as criptomoedas (representadas pelo Bitcoin) são incapazes, por definição, de exercer a função de bem público, comprometendo, portanto, o sistema de pagamentos:

Bitcoin is nothing but a disembodied monetary instrument [...] detached from any notion of the public good and disconnected from any sovereign authority that might guarantee its liquidity and perennial endurance [...] it is not supported by any hierarchically organized banking system overseen by a central bank or by a clearing system that would allow the lasting sustainability of payments to be guaranteed (Aglietta, 2018, p. 173-174).

A ausência da noção de bem público impede que as criptomoedas garantam a liquidez última em momentos de queda na economia real e destruição de riqueza privada. Dessa forma, conforme Aglietta (2018, p. 173-176), as criptomoedas são "anti-moedas”, “(...) a speculative avatar of the ideology of a world without institutions".

Fica claro que as criptomoedas não são efetivamente 'moeda' e nem ao menos 'instrumentos financeiros', ainda que se propusessem quando de sua criação a substituírem a moeda emitida pelo Estado e pelos bancos nas suas três funções. Usando o Bitcoin como exemplo, essa criptomoeda não é reserva de valor, já que seu valor não se mostrou estável ao longo do tempo. Não é universalmente aceito como meio de troca, e também não é unidade de conta. Bitcoins têm elasticidade de produção baixa, uma vez que dependem de "mineração", mas sua elasticidade de substituição é alta, sendo sua demanda facilmente substituída entre as demais criptomoedas e também entre outros ativos.

O que sustenta até então a demanda por Bitcoins é simplesmente a perspectiva de valorização no futuro. É, assim, um ativo especulativo. De acordo com Tymoigne (2013), usando os conceitos presentes no capítulo 17 da Teoria Geral de Keynes (1936), Bitcoins não têm nenhuma renda esperada $(\mathrm{q}=0)$, têm prêmio pela liquidez nulo $(\mathrm{l}=0)$, têm algum custo de 
carregamento (especialmente a energia necessária para mineração - c>0), e perspectiva de valorização/desvalorização monetária (a positivo ou negativo). A "transformação" do Bitcoin em ativo especulativo vai contra, inclusive, à concepção original de seus criadores. A "moeda" anárquica que seria capaz de fazer frente ao poderoso sistema capitalista se rendeu a agentes interessados puramente em valorização fictícia.

Além das contestações teóricas, a própria evolução das criptomoedas desafia o ideal de uma moeda digital sem Estado. Conforme ressaltado na terceira seção, a presença de intermediários financeiros, como casas de câmbio especializadas, sujeita, ainda que indiretamente, as criptomoedas à supervisão estatal, comprometendo inclusive o anonimato das transações. Ademais, a concentração e centralização do setor de mineração desafia o ideal de distribuição dos sistemas de pagamentos DLT, conferindo grande poder de validação das transações a um pequeno número de empresas. Assim, o oligopólio característico dos sistemas bancários, tão criticado pelos desenvolvedores das criptomoedas, dá lugar ao oligopólio das empresas de tecnologia. Esse movimento sugere a busca pela aceitação como algo intrínseco aos sistemas de pagamentos, já que a presença de grandes mineradores aumenta a eficácia dos sistemas DLT, confere maior segurança ao sistema e, portanto, pode estimular as transações em criptomoedas.

No entanto, as críticas apontadas acima não esgotam o potencial disruptivo das criptomoedas e dos sistemas de pagamentos DLT em relação ao sistema monetário. A entrada dos Bancos Centrais no setor aponta novos rumos para as moedas digitais por meio das criptomoedas estatais destinadas ao mercado interbancário e ao varejo, que exaurem os ideais Crypto Anarchist, já que são centralizadas e emitidas exclusivamente pela autoridade monetária, porém conservam a criptografia e o caráter peer-to-peer.

Um ponto para pesquisa futura envolve as propostas especialmente inovadoras no caso das criptomoedas estatais, que podem, inclusive, impactar a condução da política monetária. O principal desafio dos Bancos Centrais na condução da política monetária - verificados nos episódios de quantitative easing ${ }^{15}$ - é impactar o nível de renda e emprego por meio dos canais de transmissão tradicionais (canal do crédito, de ativo e dos juros). A dificuldade enfrentada pelas autoridades monetárias em atingir tais objetivos no período após a crise financeira de 2008 estimulou um intenso debate sobre os rumos da política monetária, com diversas propostas não convencionais - helicopter money ${ }^{16} \mathrm{e}$ o uso de taxas de juros nominais negativas, por exemplo (Borio; Zabay, 2016). Neste contexto, as criptomoedas estatais de varejo, como a proposta do Fedcoin, constituíram mais uma opção, pois conectariam diretamente Banco Central e público, sem a presença do sistema bancário e, portanto, sem a incerteza dos canais de transmissão, embora isso não garanta a efetividade da política monetária - considerando a relação entre moeda e incerteza estabelecida por Keynes (1936, cap. 15 e 17). As criptomoedas

(15) Quantitative easing refere-se a uma política de compra de títulos públicos e privados (ou compra de ativos) pelo Banco Central (Borio; Zabai, 2016).

(16) Conforme Borio e Zabai (2016, p. 35), o instrumento conhecido como helicopter money representa "an increase in the nominal purchasing power of economic agents in the form of a permanent addition to their money balances". 
de atacado também impactariam positivamente a operacionalização da política monetária ao melhorar a gestão de liquidez entre bancos centrais e bancos, como no caso do CAD-coin mencionado acima.

\section{Referências bibliográficas}

AGLIETTA, M. Macroeconomia financeira: mercado financeiro, crescimento e ciclos. São Paulo: Edições Loyola, 2004. v. 1.

BACK, A. A partial hash collision based postage scheme. s.1.: s.n. 1997. Disponível em: http://www.hashcash.org/papers/announce.txt. Acesso em: 25 jan. 2015.

BECH, Morten L.; GARRATT, Rodney. Central bank cryptocurrencies. BIS Quarterly Review, Sept. 2017.

BELL, Stephanie. The role of the state and the hierarchy of money. Cambridge Journal of Economics, 25, p. 149-163, 2001.

BELLUZZO, L. G. M. O capital e suas metamorfoses. São Paulo: Editora Unesp. 2012.

BELLUZZO, L. G. M.; ALMEIDA, J. G. Depois da queda: a economia brasileira da crise da dívida aos impasses do Real. Rio de Janeiro: Civilização Brasileira, 2002.

BIS. The role of central bank money in payment systems. Committee on Payment and Settlement Systems, Aug. 2003.

BLOOMBERG. Bitcoin bloodbath nears dot-com levels as many tokens go to zero. 2018. Disponível em: https://www.bloomberg.com/news/articles/2018-06-30/Bitcoin-bloodbathnears-dot-com-levels-as-many-tokens-go-to-zero. Acesso em: 4 jul. 2018.

BORIO, C.; ZABAI, A. Unconventional monetary policies: a re-appraisal. BIS Working Papers, n. 570, Jul. 2016.

CARVALHO, F. J. C. Moeda, produção e acumulação: uma perspectiva pós-keynesiana. In: SILVA, M. L. F. (Org.). Moeda e produção: teorias comparadas. Brasília: Editora UNB, 1992.

CHICK, V. Sobre moeda, método e Keynes: ensaios escolhidos. Campinas, SP: Editora da Unicamp, 2010.

CHUEN, David Lee Kuo (Ed.). Handbook of digital currency: Bitcoin, innovation, financial instruments, and big data. Academic Press, 2015.

DAI, W. b-money, s.1.: s.n. 1998.

FINANCIAL TIMES. Santander launches blockchain-based foreign exchange service. $2018 \mathrm{a}$. Disponível em: https://www.ft.com/content/1e47733e-3e2a-11e8-b9f9-de94fa33a81e. Acesso em: 4 jul. 2018.

FINANCIAL TIMES. JPMorgan weighs spin-off for blockchain Project. Disponível em: https://www.ft.com/content/4ca72d20-2e10-11e8-9b4b-bc4b9f08f381. 2018b. Acesso em: 5 jul. 2018. 
FINNEY, H. RPOW-Reusable Proofs of Work, s.l.: s.n. 2004. Disponível em: http://cryptome.org/rpow.htm. Acesso em: 25 jan. 2019.

GARRATT. CAD-coin versus Fedcoin. Nov. 2016. 8p.

GUTTMANN, R. Money as a social institution: a heterodox view of the euro. In: BELL, S. A.; NELL, E. J. (Ed.). The state, the market and the euro. Edward Elgar, 2003.

HE, Dong. Monetary policy in the digital era. IMF Finance and Development, Jun. 2018.

HUBERMAN, Gur; LESHNO, Jacob D.; MOALLEMI, Ciamac C. Monopoly without a monopolist: an economic analysis of the Bitcoin payment system. Bank of Finland Research Discussion Papers, n. 27, 2017.

KEYNES, J. M. A Teoria Geral do emprego, do juro e da moeda. São Paulo: Ed. Atlas, 1982 [1936].

KEYNES, J. M. A treatise on money: v. I: The Pure Theory of Money. The Collected Writings of John Maynard Keynes, v. V. Cambridge: Royal Economic Society, 1971.

KONING, J. P. Fedcoin. Moneyness, 9 Out. 2014. Disponível em: http://jpkoning.blogspot.com/2014/10/fedcoin.html. Acesso em: 12 dez. 2019.

MAY, T. The crypto anarchist manifesto. s.l.: s.n., 1992. Disponível em: http://www.activism.net/cypherpunk/crypto-anarchy.html. Acesso em: 25 jan. 2019.

MEHRLING, P. Modern money: fiat or credit? Journal of Post Keynesian Economics, v. 22, n. 3, 397, Spring 2000.

NAKAMOTO, S. Bitcoin: a peer-to-peer electronic cash system. 2008. Disponível em: https://Bitcoin.org/.

PETERS, Gareth; PANAYI, Efstathios; CHAPELLE, Ariane. Trends in cryptocurrencies and blockchain technologies: a monetary theory and regulation perspective. 2015.

PORTAL DO BITCOIN. Bitmain está próxima de controlar 51\% do poder de processamento da Rede Bitcoin. 2018. Disponível em: https://portaldoBitcoin.com/bitmain-controlar-51rede-Bitcoin/. Acesso em: 4 jul. 2018.

TYMOIGNE, Eric. The fair price of a Bitcoin is zero. 2 dez. 2013. Disponível em: http://neweconomicperspectives.org/2013/12/fair-price-Bitcoin-zero.html. Acesso em: 6 jul. 2018.

WILKINS, C. Canada explores digital currency: Fintech collaboration vital to unlock promise. Global Public Investor, p. 94-95, 2017.

WRAY, L. R. Trabalho e moeda hoje: a chave para o pleno emprego e a estabilidade de preços. Rio de Janeiro: Editora UFRJ/Contraponto, 1998.

WRAY, L. R.; PAPADIMITRIOU, D. B. Introduction: Minsky on money, banking and finance. In: WRAY, L. R.; PAPADIMITRIOU, D. B. (Ed.). The Elgar Companion to Hyman Minsky. Edward Elgar Publishing, 2010. 